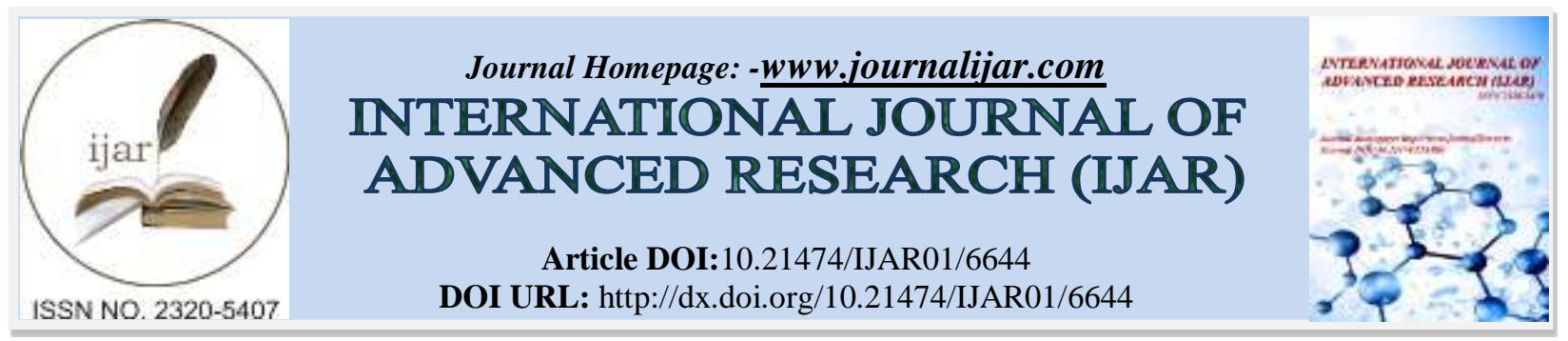

RESEARCH ARTICLE

\title{
EFFECT OF REINTRODUCTION OF GASTRIC ASPIRATE ON GASTRIC RESIDUAL VOLUME AMONG PATIENTS RECEIVING NASOGASTRIC/OROGASTRIC FEED ADMITTED IN ICUS.
}

\section{Jyoti Sharma ${ }^{1}$, Prabhjot Saini ${ }^{2}$, Shivani Kalra ${ }^{3}$ and P. L. Gautam ${ }^{4}$.}

1. College of Nursing, Dayanand Medical College and Hospital, Ludhiana, Punjab- 141001, India.

2. Professor, College of Nursing, Dayanand Medical College and Hospital, Ludhiana, Punjab- 141001, India.

3. Assistant Professor, College of Nursing, Dayanand Medical College and Hospital, Ludhiana, Punjab- 141001, India.

4. Professor \& Head Critical Care Units, Dayanand Medical College and Hospital, Ludhiana, Punjab- 141001, India.

\section{Manuscript Info}

Abstract

(...........................

Manuscript History

Received: 02 January 2018

Final Accepted: 04 February 2018

Published: March 2018

Copy Right, IJAR, 2018,. All rights reserved.

\section{Introduction:-}

Enteral feeding (EF) is considered the preferred method of nutritional support for the critically ill and has reduced septic morbidity in high risk surgical patients, decreasing catabolic response to injury, maintaining bowel mucosal integrity, decreasing translocation of gut bacteria, improving wound healing and reducing septic complications. GI dysmotility implies feeding via a NGT is often associated with large gastric residual volumes, which may lead to increase in the potential for regurgitation and vomiting as used as delay in the achievement of nutritional goals and this can be managed by closely observing gastric residual volume (GRV). ${ }_{5,6,7}$

GRV is the amount aspirated from stomach; it indicates that the GIT is functioning normally. ${ }^{7}$ The practice of measuring GRV has become a routine part of enteral feeding protocols in the critical care setting, to assess the feeding tolerance, prevent gastric emptying delay and intolerance which may lead to increase in the potential for regurgitation, vomiting and a delay in the achievement of nutritional goals; however if the GRV is more than feed is often withheld unnecessarily. US guidelines state that GRVs of less than $500 \mathrm{ml}$ should not result in termination of enteral feeding. 5,7

Disturbed GE occurs commonly in critically ill patients feed intolerance is an indirect marker of disturbed gastric motility and gastric emptying delay (GED). ${ }^{2}$ Metheney et al. also conducted a study and concluded that no consistent relationship was found between aspiration and gastric residual volumes. Although aspiration occurs without high gastric residual volumes, it occurs significantly more often when volumes are high. ${ }^{8}$

Juvé-Udina ME et al. showed that GED was almost 50\% fewer if the aspirated contents are reintroduced than when the contents are discarded. ${ }^{2}$ Some author concluded that High gastric residual volumes are not always indicative of gastric stasis, a low GRV does not protect against aspiration pneumonia. ${ }^{5}$ 
Studies have shown relationship between gastric emptying and reintroduction or discarding of the gastric aspirate to lower the risk of complications. Reintroduction of gastric aspirate lowers GRV. The number of mild and moderate gastric emptying delay episodes, doubles in those patients in whom gastric aspirate is discarded. ${ }^{10}$ Patients in intervention group showed a slightly lower total mean GRV. The number of mild and moderate gastric emptying delay episodes was double in the discard group. ${ }^{2}$

Delay in gastric emptying results in many complications. In a review of 253 patients receiving enteral nutrition via tube feedings, thirty patients $(11.7 \%)$ experienced either gastrointestinal $(6.2 \%)$, mechanical $(3.5 \%)$, or metabolic (2.0\%) complications. The most frequent cause for the failure to meet target feeding goals were slow gastric emptying as indicated by large volume gastric aspirates. ${ }^{12}$

Some authors support instilling gastric aspirate in order to contribute to the maintenance of gastric juices and the electrolyte balance (sodium and potassium levels). Nasogastric (NG) suction generates metabolic alkalosis by the loss of gastric secretions, which are rich in hydrochloric acid $(\mathrm{HCl})$. Whenever a hydrogen ion is excreted, bicarbonate ion is gained in the extracellular space and some also concluded that returning of the gastric contents can lead to nausea \& vomiting, diarrhea, clogging of tube and abdominal distension. ${ }^{10,11,12}$

Another study rendered patients to be hypochloremic by the continuous withdrawal of gastric contents through an indwelling gastric tube attached to gastric suction. The serum sodium content fluctuated. The value dropped significantly in three patients, the decrease varying from 15 to $22 \mathrm{mEq} /$ liter. And the potassium content of the serum decrease in four of the five patients, the decrement varying from 0.9 to $1.5 \mathrm{mEq} / \mathrm{liter} .{ }^{13}$

This GED can be prevented by reintroduction of gastric aspirate. It is concluded that to return or to discard gastric aspirate is a controversial issue in the nursing practice and limited studies has been conducted regarding this issue. Evidence based guidelines for enteral nutrition curtailing the incidence of complications through managing gastric residual volumes, minimizing feeding interruption, maintain electrolyte level and prevent GED in critically ill patients are very much needed. ${ }^{12}$

The current practice is discarding the gastric aspirate before each feed is continued. So the present study is planned to assess whether the reintroduction of gastric aspirate affects the gastric residual volume and maintenance of electrolytes balance. ${ }^{10,11,12}$

\section{Material and methods:-}

Research design:-

A randomized control trial design was employed using 'parallel group design' to carry out the study.

\section{Research setting:-}

The study was conducted in selected intensive care units (ICUs) of DMC \& Hospital, Ludhiana (tertiary care hospital).

\section{Inclusion \& Exclusion criteria:- \\ Inclusion criteria:-}

Patients who were:-

1. $18-60$ years of age.

2. On mechanical ventilation.

3. Getting either nasogastric/orogastric or bolus feed.

4. Available at the time of study.

\section{Exclusion criteria:-}

Patients who were:-

1. On continuous aspiration.

2. On continuous enteral feeding.

3. Above 60 years of age.

4. Having gastric surgery.

5. Admitted with Gastric motility disorders (e.g. achalasia, GERD, intestinal obstruction).

6. With-holded from feed. 
7. Admitted with tracheo-oesophageal fistula.

Sampling technique:-

Purposive sampling technique was used to draw population from target population then lottery method used for random distribution of subjects in experimental and control group.

\section{Sample size estimation:-}

Sample size estimation for randomized control trial with $\alpha$ of $0.05(95 \%)$ and power at $80 \%$.

\begin{tabular}{|c|c|}
\hline Group & Observation \\
\hline Sample size-non intervention & 535 \\
\hline Sample size-intervention & 535 \\
\hline Total & 1070 \\
\hline
\end{tabular}

For 82 patients i.e. 573 observations in (15 observations on each subject) in experimental and control group.

Total observations $=1146$

\section{Trial design:-}

After obtaining informed consent; eligible patients were randomly assigned to both groups using parallel group design

1. A experimental group - gastric aspirate was reintroduced to the patient.

2. A control group- gastric aspirate was discarded.

\section{Concealment and blinding:-}

This was a double-blinded randomized control trial where neither the patients were known about the group to which they were assigned nor the staff nurses assisting in the procedure were known about groups. Furthermore, the amount of gastric residual volume (GRV) aspirated was recorded by an observer blinded about the groups assigned to the patients.

\section{Randomization:-}

"Simple randomization method" i.e., lottery method was used to randomize the patients in experimental group and control group. Patients were having equal probability of being assigned to either of two groups. A parallel group design of randomized control was used in assigning the patients to each group. Further, a list of randomization numbers given to patients can be referred from annexure $\mathrm{v}$.

\section{Intervention:-}

1. By using purposive sampling technique subjects were drawn from target population.

2. Randomization done into two groups by using lottery method.

3. Subjects eligibility was established by using inclusion \& exclusion criteria.

4. Informed consent was obtained from the subject's relatives.

\section{Experimental group:-}

1. Each subject was followed for 15 observations.

2. Assisted in Semi-fowler position.

3. Before feeding the aspirate stomach contents to check for GRV and reintroduction of gastric aspirate was done by investigator by following reintroduction criteria.

Reintroduction Criteria ${ }^{\mathbf{2 , 2 0 , 3 7}:-}$
\begin{tabular}{|c|l|}
\hline Volume & \multicolumn{1}{c|}{ Criteria } \\
\hline$<50 \%$ & Reintroduce the gastric content. \\
\hline$>50 \%$ & Extra amount will be discarded and rest will be reintroduced. \\
\hline
\end{tabular}

NG tube flushed before feeding to prevent clogging of tube.

Feed was administered.

Bed elevated for 30-60 minutes after feeding.

Document the amount of feed, amount of aspirate reintroduce, color of aspirate. 


\section{Control group:-}

1. Each subject was followed for 15 observations.

2. Assisted in Semi-fowler position.

3. Before feeding the aspirate stomach contents to check for GRV and routine practice was followed i.e. gastric aspirate discarded.

4. Feed was administered.

5. Bed elevated for 30-60 minutes after feeding.

6. Document the amount of feed, amount of aspirate, color of aspirate.

7. Then comparison and assessment of the pre-interventional and post interventional gastric residual volume among subjects was done in both groups.

\section{Description of tool:-}

A tool consisting of three parts i.e. socio-demographic profile (part A); clinical profile (part B); assessment of gastric residual volume (GRV) and a protocol on 'reintroduction of gastric aspiration' were developed after reviewing the relevant literature and consultation with the expert. The socio-demographic profile consisted of information regarding patients age, gender, marital status, habitat, occupation, smoking, dietary pattern and life style. The clinical profile consisted of medical diagnosis, previous operative history, body built, position, DVT prophylaxis, hospitalization (in days), day of intubation, vital signs, ventilation profile, GCS, medication history, DVT prophylaxis, fluid balance, drug history, ABG values \& laboratory reports. The gastric residual volume assessment tool was used to measure the type and time of last feed, bowel sounds, intake/output, abdominal girth before and after observations, level of GED (as per criterion measure), amount and colour of aspirate, amount of aspirate reintroduced, amount of feed, and associated problems like nausea, vomiting and abdominal distension. Content validity of each tool was established by circulating the tool among expert in the deptt. of critical care medicine and medical surgical nursing.

Data was analysed using descriptive statistics (percentage, mean and standard deviation) inferential statistics $\left(\chi^{2}, \mathrm{t}\right.$ test). A p value of 0.05 was taken as a threshold to test the significance level.

\section{Results:-}

Socio-demographic profile of the subjects in experimental and control group:-

Out of 82 subjects i.e. experimental $\left(n_{1}=42\right)$ with mean age $51.90 \pm 11.62$ and control group $\left(n_{2}=40\right)$ with mean age 46.3 \pm 14.99 . Most of subjects were male, married, working, smoker and had a moderate life style pattern. While most of subjects belonged to urban area in experimental group and equal number of subjects in rural and urban area in control group. All the groups were statistically identical ( $\mathrm{p}>0.05)$.

\section{Aspiration volume among experimental and control groups.:-}

Table I showed that the aspiration volume in both groups. The average aspiration volume in experimental group $(8.13 \pm 26.89)$ was significantly lower than the control group (18.26 \pm 48.08$), \mathrm{p}=0.000$ and feeding volume was $152.06 \pm 68.74 \& 175.11 \pm 73.01$ in experimental and control group respectively. The mean ratio in experimental and control group was 18.70 vs. 9.59 (lower the value, higher the aspiration volume). T test was applied to evaluate the difference of aspiration volume between both the groups. There was a significantly higher aspiration volume in control group $(\mathrm{p}=0.000)$ than in experimental group.

\section{Gastric emptying delay in both groups:-}

Table II showed that the [45(7.86\%) vs. 87(15.18\%)] GED episodes were observed in experimental and control group. As per the levels of GED, experimental group showed $50 \%$ fewer episodes than control group in terms of mild $[10(1.74 \%)$ vs. $22(3.84 \%)]$, moderate $[15(2.62 \%)$ vs. $24(4.18 \%)]$, severe [20(3.5\%) vs. 41(7.16\%)] in experimental and control group respectively. Chi-square $\left(\chi^{2}\right)$ was applied to evaluate the gastric emptying delay in both groups. Control group was having significantly $(\mathrm{p}=0.0013)$ higher GED (gastric emptying delay) as compared to experimental group $(\mathrm{p}=0.0013)$.

\section{Comparison of GED among experimental and control group as per relative risk and odd ratio:-}

Table III showed that the Comparison of GED among experimental and control group as per relative risk and odds ratio. In control group relative risk of developing GED is 0.517 times while Odds of occurrence of GED in control group is 0.47 times the odds of occurrence in experimental group ( $R R$ and $O R<1, p=0.0001)$. 
Problems observed in patients after feeding in both groups:-

Table IV showed that the problems observed in patients after feeding in both groups. 04(9.52\%) in experimental group and $02(5 \%)$ in control group complained of having nausea \& vomiting, while $4(9.52 \%)$ in experimental group and $2(5 \%)$ in control group complained of abdominal distension. No other problems were documented or observed in both groups namely aspiration, diarrhea and clogging of tube.

\section{Mean abdominal girth in experimental and control group:-}

Table $\mathbf{V}$ showed that the mean abdominal girth of experimental and control group which was found to be (108.30 \pm $14.71 \& 114.03 \pm 12.99)$ respectively, depicting that average abdominal girth was found to be more in control group than experimental group $(\mathrm{p}=0.012)$.

\section{Association of socio-demographic variables with GED:-}

The association of socio-demographic variables. As per age, experimental group showed more episodes of GED 35 in 49-60 years as compared to control group 39 of GED which was found in 18-30 years age group, $\mathrm{p}=0.000$.

As per body built, experimental group showed more episodes of GED 24 in moderate body built while in control group 44 of GED was found in moderate body built. Male $(\mathrm{p}=0.22)$, smokers $(\mathrm{p}=0.09)$, moderate life style pattern $(\mathrm{p}=0.19)$ and those not receiving DVT prophylaxis $(\mathrm{p}=0.11)$ showed more GED episodes. Therefore it concluded that there were significant association of younger age (18-30) and body built with GED (gastric emptying delay) $(\mathrm{p}=0.000)$.

Table I:- Aspiration volume among experimental and control group. $\mathbf{N = 1 1 4 6}$

\begin{tabular}{|c|c|c|c|}
\hline \multirow{2}{*}{ Variables } & Experimental group $\left(\mathbf{n}_{\mathbf{1}}=\mathbf{5 7 3}\right)$ & Control group $\left(\mathbf{n}_{\mathbf{2}}=\mathbf{5 7 3}\right)$ & \multirow{2}{*}{ t test } \\
\cline { 2 - 4 } & Mean \pm SD & Mean \pm SD & \\
\hline Aspiration volume $(\mathrm{ml})$ & $8.13 \pm 26.89$ & $18.26 \pm 48.08$ & $\mathrm{t}=4.396$ \\
& & & $\mathrm{df}=1144$ \\
& & $175.11 \pm 73.01$ & $\mathrm{p}=0.000^{*}$ \\
\hline Feeding volume $(\mathrm{ml})$ & $152.06 \pm 68.74$ & & $\mathrm{t}=5.503$ \\
& & $\mathrm{df}=1144$ \\
& 18.70 & 9.59 & $\mathrm{p}=0.000^{*}$ \\
\hline Mean ratio & & & \\
\hline
\end{tabular}

$*=$ significant $\mathrm{p}<0.05$.

\#Mean ratio= feeding volume (ml)/ aspiration volume (ml)

Table II:- Distribution of subjects as per gastric emptying delay (GED). $\mathbf{N}=\mathbf{1 1 4 6}$

\begin{tabular}{|c|c|c|c|}
\hline & $\begin{array}{c}\text { Experimental group } \\
\left(\mathrm{n}_{1}=573\right)\end{array}$ & $\begin{array}{c}\text { Control group } \\
\left(n_{2}=573\right)\end{array}$ & \multirow[t]{2}{*}{$\chi^{2}$ Statistics } \\
\hline GED & $\mathbf{f}(\%)$ & $f(\%)$ & \\
\hline Normal $(\leq 20 \%)$ & $528(92.14)$ & $486(84.82)$ & \multirow{4}{*}{$\begin{array}{c}15.52 \\
\mathrm{df}=3 \\
\mathrm{p}=0.0013^{*}\end{array}$} \\
\hline Mild (21-30\%) & $10(01.74)$ & $22(03.84)$ & \\
\hline Moderate $(31-50 \%)$ & $15(02.62)$ & $24(04.18)$ & \\
\hline Severe $(>50 \%)$ & $20(03.50)$ & $41(07.16)$ & \\
\hline
\end{tabular}

$*=$ significant $\mathrm{p}<0.05$.

Average aspiration volume: exp. Gp (8.13 \pm 26.89$)$, control group (18.26 \pm 48.08$)$.

GED: exp.gp.45 (7.86\%), control group 87(15.18\%).

Table III:- Comparison of GED among experimental and control group as per relative risk and odd ratio. N=1146

\begin{tabular}{|c|c|c|c|c|}
\hline $\begin{array}{c}\text { Gastric } \\
\text { emptying delay } \\
\text { (GED) }\end{array}$ & $\begin{array}{c}\text { Experimental } \\
\text { group } \\
\text { (Exposed) }\end{array}$ & $\begin{array}{c}\text { Control } \\
\text { group } \\
\text { (Non-exposed) }\end{array}$ & $\begin{array}{c}\text { Total } \\
(\mathrm{N}=1146)\end{array}$ & $\begin{array}{c}\text { Relative Risk } \\
\text { Odds Ratio }\end{array}$ \\
\hline Yes & 45 & 87 & 132 & \multirow{2}{*}{$\begin{array}{r}\mathrm{RR}=0.517 \\
\mathrm{OR}=0.476 \\
95 \% \mathrm{CI}=0.36-0.72 \\
\mathbf{p}=\mathbf{0 . 0 0 0 1} \%\end{array}$} \\
\hline No & 528 & 486 & 1014 & \\
\hline
\end{tabular}


Randomized Control Trial Design.

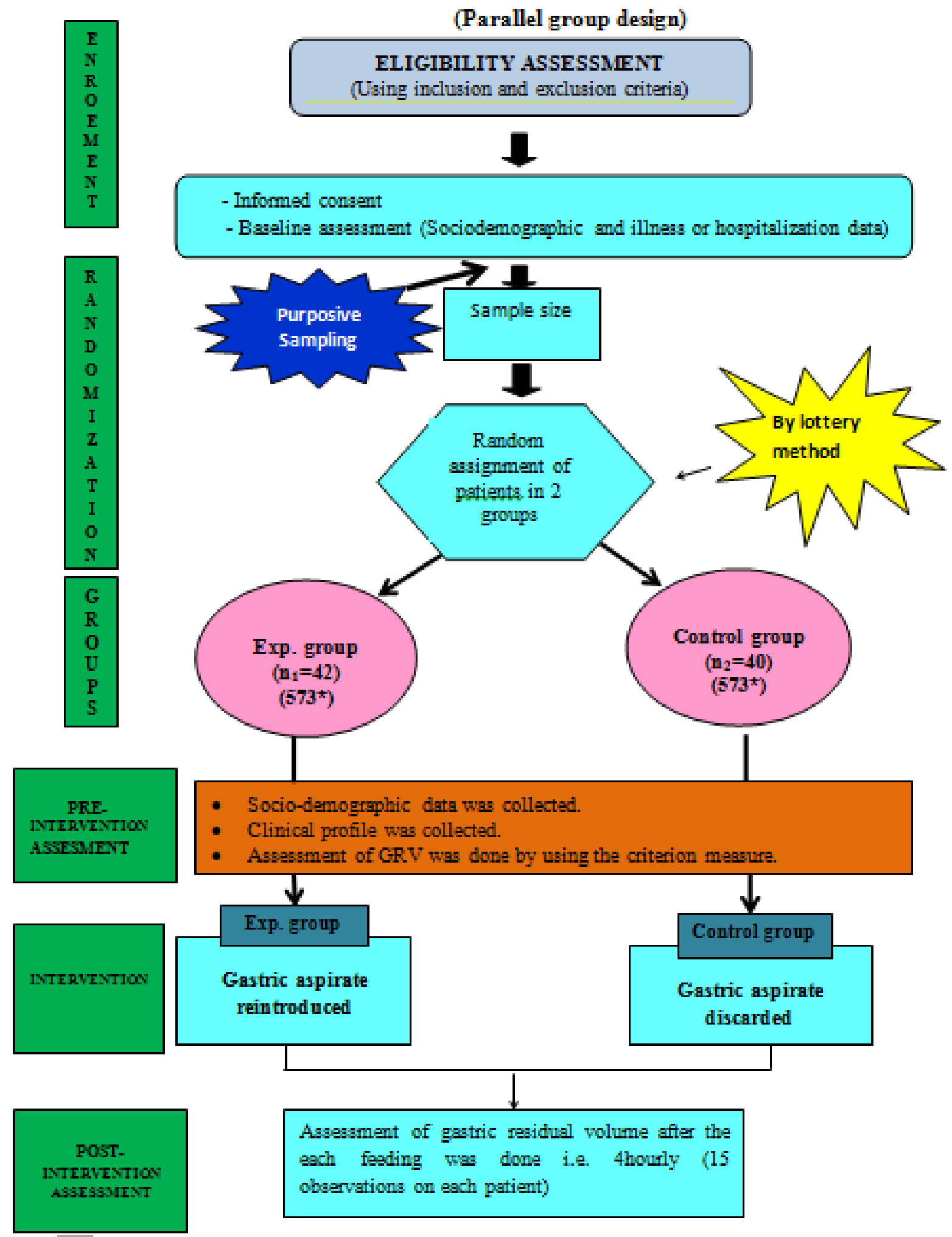


Table IV:- Problems observed in patients after feeding in both groups $\quad \mathbf{N}=\mathbf{8 2}$

\begin{tabular}{|c|c|c|c|}
\hline Problems & $\begin{array}{c}\begin{array}{c}\text { Experimental group } \\
\left(\mathrm{n}_{\mathbf{1}}=\mathbf{4 2}\right)\end{array} \\
\mathbf{f}(\%)\end{array}$ & $\begin{array}{c}\begin{array}{c}\text { Control group } \\
\left(\mathbf{n}_{2}=40\right)\end{array} \\
\mathbf{f}(\%)\end{array}$ & $\chi^{2}$ statistics \\
\hline $\begin{array}{c}\text { Nausea \& vomiting } \\
\text { Yes } \\
\text { No }\end{array}$ & $\begin{array}{l}04(09.52) \\
38(90.48)\end{array}$ & $\begin{array}{l}02(05.00) \\
38(95.00)\end{array}$ & $\begin{array}{c}0.613 \\
\mathrm{df}=1 \\
\mathrm{p}=0.431\end{array}$ \\
\hline $\begin{array}{c}\text { Abdominal distension } \\
\text { Yes } \\
\text { No }\end{array}$ & $\begin{array}{l}04(09.52) \\
38(90.48)\end{array}$ & $\begin{array}{l}02(05.00) \\
38(95.00)\end{array}$ & $\begin{array}{c}0.613 \\
\mathrm{df}=1 \\
\mathrm{p}=0.431\end{array}$ \\
\hline
\end{tabular}

$\mathrm{NS}=$ Non - significant $\mathrm{p}>0.05$.

No case of Aspiration, clogging of tube and diarrhea was reported

Table V:- Mean abdominal girth in experimental and control group. $\quad \mathbf{N}=\mathbf{8 2}$

\begin{tabular}{|c|c|c|c|}
\hline Variable & $\begin{array}{c}\text { Experimental group } \\
\left(n_{1}=42\right) \\
\text { Mean } \pm \text { SD }\end{array}$ & $\begin{array}{c}\text { Control group } \\
\left(\mathrm{n}_{2}=40\right) \\
\text { Mean } \pm \text { SD }\end{array}$ & t test \\
\hline Abdominal Girth & $108.30 \pm 14.71$ & $114.03 \pm 12.99$ & $\begin{array}{c}\mathrm{t}=-2.54 \\
\mathrm{df}=80 \\
\mathbf{p}=\mathbf{0 . 0 1 2}\end{array}$ \\
\hline
\end{tabular}

$*=$ significant $\mathrm{p}<0.05$.

\#Abdominal girth was measured twice (before feed) i.e. $\mathrm{O} 1$ and $\mathrm{O} 15$

\section{Discussion:-}

A randomized control trial was conducted on 82 subjects receiving nasogastric/orogastric feed and effects of reintroduction of gastric aspirate was assessed on GRV and results revealed that the average aspiration volume in experimental group was $8.13 \pm 26.89$ while in control group it was significantly higher i.e.18.26 \pm 48.08 ( $\mathrm{p}=0.000$ ). The mean ratio of gastric content reintroduction in experimental and control group was 18.70 vs 9.59 respectively.

Similar findings are reported by Devinder Kaur $^{20}$ et al. (2013) in PGIMER, Chandigarh showing the average aspiration volume in test group was $18.0 \pm 8.0$ while in control group it was $25 \pm 14.6$ ( $\mathrm{p}=0.11$ ). Another studies by Juvé-Udina ${ }^{2}$, et al in 2009 and KJ Booker ${ }^{21}$ et al. (2000) supported the above findings that patients in the intervention group showed a slightly lower total mean GRV $(\mathrm{p}<0.11)$. Mean ratio of gastric content reintroduction in intervention group was $0.93 \pm 0.25$. The study results were contradicted by Parker Leslie ${ }^{19}$ et al. (2015) which concluded that on the basis of various reviews those decisions to discard and re-feed GRs are based on judgment, beliefs and experience as well as unit tradition.

The present study revealed that GED was almost 50\% fewer if the aspirated contents are reintroduced than when the contents are discarded. Study revealed that GED was higher in Control group than in experimental group with Mild GED (3.83\% vs. $1.74 \%)$, Moderate GED (4.18\% vs. $2.62 \%)$ and severe GED (7.15\% vs. 3.5\%) respectively. The above findings are supported by Juvé-Udina ${ }^{2}$, et al in 2009 at Spain and Amoura ${ }^{7}$ et al. (2014) at Egypt that GED was almost $50 \%$ fewer if the aspirated contents are reintroduced than when the contents are discarded. Returning gastric aspirate up to $250 \mathrm{ml}$ does not contribute to gastric and associate complications as measured by Gastric residual volume and gastric emptying delay.

The present study was contradicted by Davinder Kaur ${ }^{20}$ et al. (2013) which concluded that that reintroducing of gastric aspirate had no effect on gastric emptying. Another study by Amoura ${ }^{7}$ et al. (2014) showed that there was a statistical significant difference between study $\&$ control groups in relation to gastric emptying delay on $7^{\text {th }}$ day, the study group had less mean level than control group, moreover, there was a statistical significant difference in pulse and respiration among control group before and after feeding procedure. 
The present study shows that in control group RR of developing GED was 0.517 times while Odds of occurrence of GED in control group was 0.47 times the odds of occurrence in experimental group. $(\mathrm{RR}$ and $\mathrm{OR}<1, \mathrm{p}=0.0001)$. There was no supported or contradictory study about the RR and odds of occurrence of GED.

The present study also revealed that there was a significant association of electrolyte imbalance $\left(\mathrm{Na}^{+}\right.$and $\left.\mathrm{K}^{+}\right)$with GED ( $p=0.000)$. GED was observed more in discard group as compared to reintroduction group (87 Vs 45). Normal serum sodium levels were observed to be more associated with GED in discard group than in reintroduction group (54 vs 34) respectively. Hypernatremia was associated with GED in discard group than reintroduction group (27 vs 0) respectively. Normal serum potassium levels in discard group (87 out of 87 ) was associated with GED as compared to 35 out of 45 in reintroduction group, similarly 10 out of 45 observations with hyperkalemia were associated with GED as compared to none in discard group. Thus the study revealed that GED was significantly associated with hyponatremia and hyperkalemia in reintroduction group and hypernatremia in discard group.

The findings were supported by Bellet ${ }^{43}$ et al. (2012), Booker $^{21}$ et al. (2000), Cataldi Betcher ${ }^{23}$ (1983) and Ariel ${ }^{13}$ et al. (1954 that there was significant difference in serum sodium and potassium if contents were discarded. Discarding gastric aspirate may result in loss of gastric fluids and electrolytes (Cataldi-Betcher ${ }^{23}$ et al., 1983) However Devinder Kaur ${ }^{20}$ et al. (2012) and Booker ${ }^{21}$ et al. (2000) contradicted the findings of that there were no significant differences in serum electrolytes level in both groups.

The present study revealed the problems i.e. nausea, vomiting and abdominal distension were observed in similar frequency in both groups. The similar findings were reported by Juvé-Udina ${ }^{2}$, et al in 2009 and Devinder Kaur ${ }^{20}$ et al. (2013) reporting that patients have equal episodes of vomiting and diarrhea and abdominal pain in both groups. Juvé-Udina ${ }^{2}$, et al in $\mathbf{2 0 0 9}$ also revealed that reintroducing the gastric content aspirated up to $250 \mathrm{ml}$ per check, does not increase the number or the severity of complications

The present study shows the mean abdominal girth before and after giving feed in control group $114.03 \pm 12.99$ was significantly higher than experimental group $108.3 \pm 14.71(\mathrm{p}=0.012)$. The above findings supported by Devinder Kaur $^{20}$ et al. (2013) and Juvé-Udina ${ }^{2}$, et al in 2009 found that the difference in mean abdominal girth before and after giving feed in control group $1.12 \pm 0.32$ was higher than test group $1 \pm 0.23(\mathrm{p}=0.08)$.

The present study revealed no case of aspiration in both reintroduction and discarding group probably due to the elevated position (head-of-bed at $30^{\circ}$ elevation) as most (100\%) provided position in both groups. The study is supported by Stevens ${ }^{39}$ et al., 2002 revealing that patients were kept at safety position (head-of-bed at $30^{\circ}$ elevation) and continuous ENT delivery via peristaltic pump assured constant delivery of small volumes in the stomach). These factors have probably contributed to reduce aspiration risk.

Some authors (De Boer ${ }^{40}$ et al., 1992; Mallampalli ${ }^{41}$ et al., 2000; Zhao $^{42}$ et al., 2006) described the important role of hyperglycaemia in oesophageal motility, decreasing inferior oesophageal sphincter pressure, the speed of the oesophageal peristalsis, and in the delay of gastric emptying and this was supported by the present study revealing that mean blood sugar levels in discard group was higher as compared to reintroduction group (169.75 \pm 57.46 vs $157.66 \pm 55.65)$ respectively. Hyperglycemia was observed to be associated more with GED in discard group than reintroduction group (38 vs 21) which could be a probable cause of GED in control group than experimental group $(\mathrm{p}=0.196)$.

The present study shows that there is significant association of younger age (18-30) and body built with GED (gastric emptying delay) ( $\mathrm{p}<0.05)$. Male, smokers, moderate life style pattern and not receiving DVT prophylaxis showed more GED episodes. Above findings are supported by Naugen ${ }^{\mathbf{1 2}}$ et al. (2007) in US that there was a significant association of older age with gastric emptying. The studies by Juvé-Udina ${ }^{2}$, et al in 2009 at Spain and Amoura $^{7}$ et al. in (2014) at Egypt contradict the findings concluding that there is no significant differences found with regard to socio-demographic variables and secondary diagnosis, MV. 


\section{References:-}

1. Suddarth's \& Brunner. Textbook of Medical-Surgical Nursing. Assessment of digestive and gastrointestinal functions. $11^{\text {th }}$ ed. Vol.1. Wolters Kluwer; 2008. P. 1121-22.

2. Udina J, Valls M, Carreno G, Martinez E, Moutude P, Domingo F et al. To return or to discard? Randomized trial on gastric residual volume management. Inyensive Crit Care Nurs 2009; 25: 258-67.

3. Alex Mejia, Walter K Kraft. Acid Peptic Diseases: Pharmacological Approach to Treatment [internet]. Place unknown: Medscape Publishers; 2009 [unknown]. Available from: http://www.medscape.com/viewarticle/705418_2.

4. Quigley EMM. Critical care dysmotility: Abnormal foregut motor function in the ICU/ITU patient. J Gastroenterology and Hepatology 2005; 54: 1351-52.

5. Williams TA, Leslie GD. A review of the nursing care of enteral feeding tubes in critically ill adults. Inyensive Crit Care Nurs 2004; 20(6): 330-43.

6. Moore FA, Feliciano DV, Andrassy RJ, McArdle AH, Booth FV, Morgenstein-Wagner TB et al. Early enteral feeding, compared with parenteral, reduces postoperative septic complications. The results of a meta-analysis. Ann of Surg 1992; 216: 172-83.

7. Behairy S.A. Salah D. Effect of returning versus discarding gastric aspirate on the occurrence of gastric complications and comfort outcomes on enteral feeding patients. IJONS 2014; 4(15): 21-9.

8. NA Metheny, OL Schallom, DA Oliver, RE Clouse. Gastric residual volume and aspiration in critically ill patients receiving gastric feedings. Am J Crit Care 2008 Nov; 17(6): 512-20.

9. Kaladeh Al Mahmoud. A review of current nursing practice and evidence based guidelines in enteral nutrition in critically ill patient. ESJ 2012; 8(30): 66-86.

10. Gastric Emptying Study [online] Accessed on: 7, 2014. [cited 2015 march 24]. Available at: http://www.medicinenet.com/emptying_study /article.htm.

11. Heyland DK, Tougas G, King D, Cook DJ. Impaired gastric emptying in mechanically ventilated, critically ill patients. Intensive Care Med 1996; 22(12): 1339-44.

12. Nguyen NQ, MeiPN, Chapman M, Fraser R, Hallway HR. The impact of admission diagnosis on gastric emptying in critical ill patients. Crit. care 2007; 11(1): 1-10.

13. Ariel IM. The effects of acute hypochloremia on the distribution of body fluid and composition of tissue electrolytes in man. Ann Sur 1954 Aug; 140(2): 150-63.

14. Bing Guo. Gastric residual volume management in critically ill mechanically ventilated patients: A literature review. Proceedings of Singapore Healthcare 2015; 24(3): 171-80.

15. Arazberdi Ghochae, Mitra hekmat fshar, Ghilamreza Amin, Mohammed Ali Vakili, Samira Eshghi Nia, Akram Sanagoo et al. The survey of the effect of ginger extract on gastric residual volume in mechanically ventilated patients hospitalized in the Intensive Care Units. AEB 2013 Oct; 7(11): 3395-400.

16. Chien-Wei Hsu, Shu-Fen Sun, David Lin Lee, Shoa-Lin Lin, Kam-Fai Wong, Hsiu-Hua Huang et al. Impact of disease severity on gastric residual volume in critical patients. WJG [internet]. 2011 April [cited 2011 April]. 17(15). Available from http://www.wjgnet.com/1007-9327/pdf/v17/i15/2007.pdf.

17. HJ Peter, ZF Durk. Comparison between the supine and prone positions. A prospective cross over study in mechanically ventilated patients. Crit Care 2001; 5: 216-20.

18. Pinilla, J, Samphire J, Arnold C, Liu L, Thiessen B. Comparison of gastrointestinal tolerance to two enteral feeding protocols in critically ill patients: A prospective, randomized controlled trial. JPEN 2001; 25(2): 81-6.

19. Leslie Parker, Roberto Murgas Torrazza, Yuefeng Li, Elizabeth Talaga, Jonathan Shuster, Josef Neu. Aspiration and Evaluation of Gastric Residuals in the NICU: State of the Science. J Perinatal Neonatal Nurse 2015; 29(1): 51-9.

20. Kaur D, Agnihotri M, Kaur S, Narayanan S. Effect of reintroduction of aspirated gastric content on gastric emptying in patients receiving nasogastric/orogastric feed admitted in intensive care units: A randomized control trial. J Nurse Midwifery 2013; 9(2): 73-80.

21. Booker KJ, Niedringhaus L, Eden B, Arnold JS. Comparison of 2 methods of managing gastric residual volumes from feeding tubes. Am J Crit Care 2000 Sep; 9(5): 318-24.

22. Kaur D, Agnihotri M, Kaur S, Narayanan S. Effect of reintroduction of aspirated gastric content on serum electrolytes levels of patients receiving nasogastric/orogastric feed admitted in intensive care units: A randomized control trial. J Nurse Midwifery 2012; 8(2): 162-68.

23. Cataldi-Betcher EL, Murray H. Seltzer MH, Jones KW. Complications Occurring duringEnteral Nutrition Support: A Prospective Study. J Parenteral Enteral Nutr 1983; 7: 546-55. 
24. Xiaowen Hu, Eunhee S. Yi, Jay H. Ryu. Aspiration-Related Deaths in 57 Consecutive Patients: Autopsy Study. PLoS ONE [internet]. 2014 July [cited 2014 July 30]. 9(7). Available from: http://journals.plos.org/plosone/article?id=10.1371\%2Fjournal.pone.0103795.

25. Samantaray Aloka. Pulmonary aspiration of gastric contents: prevention and prophylaxis. J Clin Sci Res 2014; 3: 243-50.

26. Jean Reignier, Emmanuelle Mercier, Amelie Le Gouge, Thierry Boulain, Arnaud Desachy, Frederic Bellec et al. Effect of Not Monitoring Residual Gastric Volume on Risk of Ventilator-Associated Pneumonia in Adults Receiving Mechanical Ventilation and Early Enteral Feeding: A Randomized Controlled Trial. JAMA. 2013 Jan 16; 309(3): 249-56.

27. Kwong JC, Howden BP, Charles PG; New aspirations: the debate on aspiration pneumonia treatment guidelines. Med J Aust. 2011 Oct 3; 195(7): 380-1.

28. Emine Alp, Andreas Voss. Ventilator associated pneumonia and infection control. Ann Clin Microbiol Antimicrob. 2006 April; 5: 1-11.

29. Gomes GF, Pisani JC, Macedo ED, Campos AC. The nasogastric feeding tube as a risk factor for aspiration and aspiration pneumonia. Curr Opin Clin Nutr Metab Care 2003 May; 6(3): 327-33.

30. Johnson JL, Hirsch CS. Aspiration pneumonia. Recognizing and managing a potentially growing disorder. Postgrad. Med. J 2003 Mar; 113(3): 99-102.

31. DeLegge MH. Aspiration pneumonia: incidence, mortality, and at-risk populations. JPEN J Parenter Enteral Nutr 2002 Nov; 26(6): 19-24.

32. Annamma Jacob. Clinical nursing procedures: The art of nursing practice. Administration of nasogastric tube feeding $2^{\text {nd }}$ ed. Jaypee brothers; 2010. P. 180-82.

33. Nancy Sr. Principles and practice of Nursing. Nutrition. $6^{\text {th }}$ ed. N.R. Publishing house; 2010. P. 398-404.

34. Lippincott Wiliams and Wilkins. Manual of Nursing practice. Nutritional problems. $10^{\text {th }}$ ed. Wolters Kluwer; 2010. P. 745-46.

35. Holland Kimberly. Nasogastric intubation and feeding [internet]. Place unknown: Health line; 2013 [cited on 2015 March 6]. Available from: http://www.healthline.com/health/ nasogastric-intubation-and-feeding.

36. K.G Kreymann, M.M Berger, N.E.P Deutz, M. Hiesmayr, P.Jolliet, G. Kazandjiev et al. ESPEN guidelines on enteral nutrition [internet]. Place unknown: Elsevier; 2006 [cited on 2015 Jan 20]. Available from: www.hugge.ch $>$ files $>$ structure $>$ enicu.

37. Lovett Michele. Standard gastric residual volumes (GRV) protocol [internet]. Place unknown: unknown; 2013 $\begin{array}{lllllll}\text { [cited } & \text { on } & 2015 & \text { April } & 2] & \text { Available } & \text { from }\end{array}$ https://www.utoledo.edu/policies/utmc/nursing/guidelines/general/pdfs/standard_gastric_residual_volumes_grv _protocol_guidelines.pdf.

38. Kevin M. Sullivan, Fleiss. Sample Size--Unmatched Case Control Study [internet] place unknown: publisher unknown; 2007 [cited on 2015 Feb 6]. Available from: http://www.openepi.com/v37/SampleSize/SSCohort.htm.

39. Steevens EC, Lipscomb AF, Poole GV, Sacks GS. Comparison of continuous vs intermittent nasogastric enteral feeding in trauma patients: perceptions and practice. Nutr Clin Pract 2002; 17 (2): 118-22.

40. De Boer SY, Masclee AA, Lam WF, Lamers CB. Effect of acute hyperglycemia on esophageal motility and lower esophageal sphincter pressure in humans. Gatroenterology 1992; 103 (3): 775-80.

41. Mallampalli A, McClave SA, Snider HL. Defining tolerance to enteral feeding in the intensive care unit. Clin Nutr 2000; 19 (4): 213-15.

42. Zhao J, Frokjaer JB, Drewes AM, Ejskjaer N. Upper gastrointestinal sensorymotor dysfunction in diabetes mellitus. World J Gastroenterol 2006; 12 (18): 2846-57.

43. Bellet S, Nadler CS, Gazes PC, Lanning M. The effect of vomiting due to intestinal obstruction on the serum potassium. Gastroenterology 1949; 12(1): 49-56. 